\title{
Angiopoietin-like proteins - their role in lipoprotein metabolism and association with atherogenic dyslipidemia
}

\author{
Corresponding author: \\ Karolina Murawska, Department \\ of Laboratory Medicine, Collegium \\ Medicum, Nicolaus Copernicus \\ University, Sklodowskiej-Curie Street 9 \\ 85-094 Bydgoszcz, Poland \\ phone: + 48525854046 \\ fax: +48525853603 \\ e-mail: karolina.murawska@yahoo.com \\ Medical Research Journal 2018; \\ Volume 3, Number 3, 175-178 \\ 10.5603/MRJ.2018.a0027 \\ Copyright (C) 2018 Via Medica \\ ISSN 2451-2591
}

\begin{abstract}
Scientists have been trying to find the best parameter for laboratory assessment of the risk of cardiovascular diseases (CVD) for decades. Initially, the results of many studies indicated that the analysis of the lipid profile was sufficient to evaluate the risk of CVD. Further studies revealed that more precise laboratory prediction of cardiovascular risk requires quantification of atherogenic lipoproteins. Recently, angiopoietin-like proteins 3, 4 and 8 (ANGPTLs) have been described as important regulators of plasma lipoprotein metabolism and triglyceride homeostasis. Mutations in ANGPTL3 leading to loss of its function have been linked to decreased risk of CVD in humans. Among potential new targets for the management of dyslipidemia, ANGPTL3 may become a considerably promising one.

Key words: angiopoietin-like proteins, apolipoprotein B, cardiovascular disease, lipoprotein lipase, triglycerides
\end{abstract}

Med Res J 2018; 3 (3): 175-178

\section{Introduction}

Cardiovascular diseases are considered to be a serious problem of the 21 st Century. In Poland, in spite of the increased number of invasive interventions, cardiovascular diseases are still the cause of more than 35 percent of deaths in individuals before the age of 64 . The most common cause of cardiovascular diseases $(>90 \%)$ is coronary atherosclerosis, which is a chronic inflammatory process. Some other causes of the disease are coronary artery spasm, an embolism or injury of a coronary artery. The risk factors for the occurrence of CVD include lipid disorders, hypertension, cigarette smoking, obesity, stress, diabetes, low physical activity, hyperhomocysteinemia and an inappropriate diet. The risk factors that are non-modifiable and can also lead to disease comprise the family history of coronary artery disease, gender and age [1].

Routine laboratory assessment of the cardiovascular risk, in general, includes the traditional lipid profile measurement. The key components are: calculated or measured LDL-cholesterol (LDL-C), HDL-cholesterol (HDL-C) and triglycerides (TG), measured with direct methods. Increased levels of lipids are an important risk factor for atherosclerosis development. Additional tests, which are not carried out routinely but are char- acterised by their high diagnostic value, include the measurements of apolipoproteins: $a p o B$ and apoA-I and lipoprotein (a). Estimation of the ratio of apoB/apoA-I, total cholesterol (TC) to HDL-C or calculation of nonHDL cholesterol enables a better assessment of the risk of CVD [2].

Cholesterol level is a significant predictor of cardiovascular risk, however, despite its decrease after treatment, there is still a risk of ischaemic heart disease [3]. It is related to LDL particles heterogeneity and the low level of HDL-C. The occurrence of small, dense LDL particles correlates with the presence of triglyceride-rich lipoproteins and a lowering of the HDL-C level. Small, dense LDL particles are more atherogenic and their number reflects the level of apolipoprotein $B(A p o B)$.

Numerous studies indicated that there is also a significant correlation between the small, dense LDL and the risk of ischaemic heart disease. It has been shown that the presence of small, dense LDL may increase the risk by 7 times [4-7].

\section{Lipoprotein lipase (LPL)}

Lipoprotein lipase (LPL) is a key enzyme taking part in triglyceride metabolism. LPL is produced in macrophages, adipose tissue, heart and skeletal mus- 


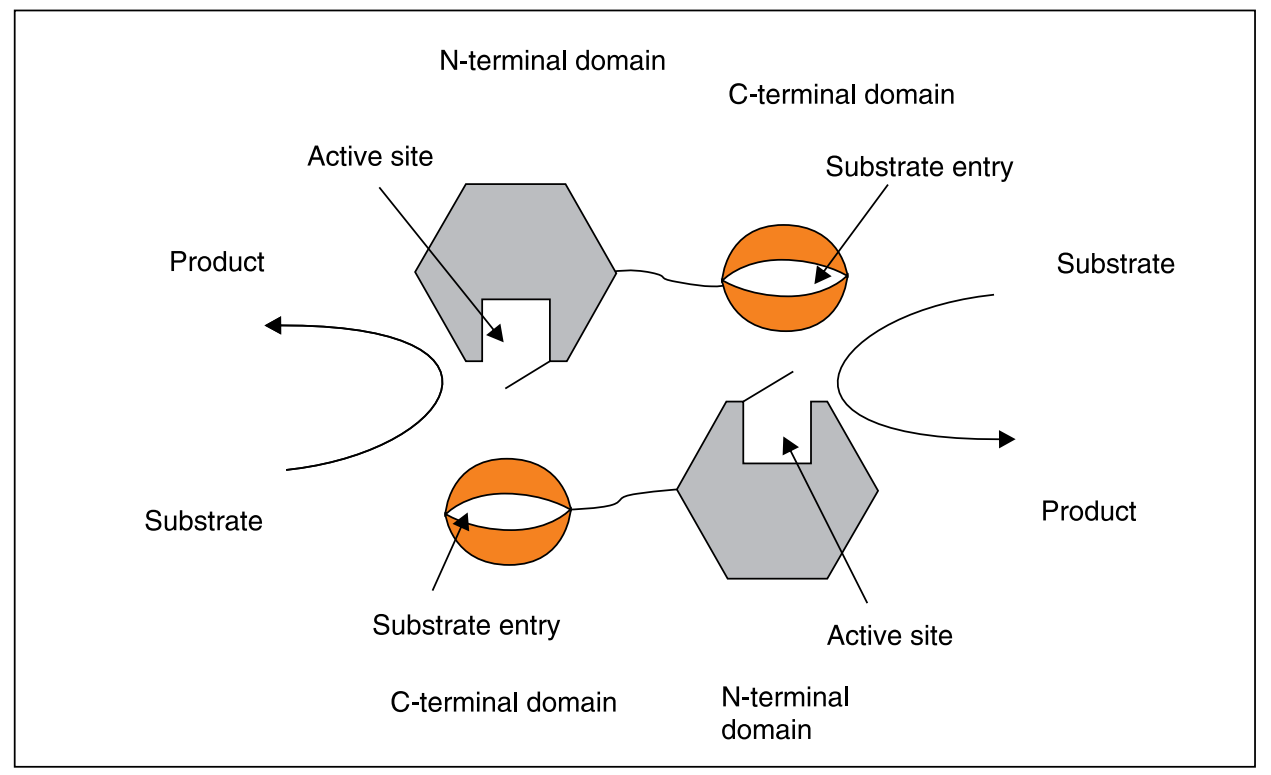

Figure 1. Lipoprotein lipase domains function [8], modified by authors.

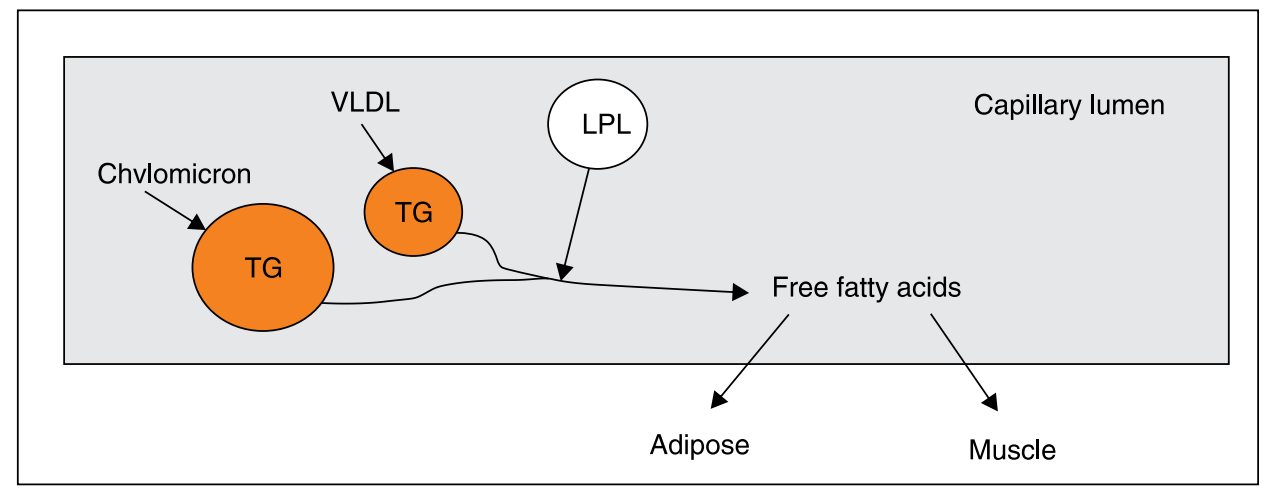

Figure 2. Lipoprotein lipase action [9], modified by authors

cles. The enzyme is secreted from parenchymal cells (e.g. adipocytes, cardiomyocytes) as a homodimer. Lipoprotein lipase consists of two domains: a larger N-terminal domain, which contains the lipolytic active site and apolipoprotein interaction site, and the smaller $\mathrm{C}$-terminal domain which is responsible for the substrate specificity. The domains are linked by a peptide bond. Lipoprotein lipase is functional as the head-to-tail dimer (Fig.1).

LPL is transported by glycosylphosphatidylinositol anchored high-density lipoprotein-binding protein 1 (GPIHBP1) to the vascular lumen to become functional at the endothelial cells surface [8]. The regulation of LPL occurs at the level of transcription by peroxisome proliferator-activated receptor PPAR $\alpha$ (in the liver) and PPAR $\gamma$ (in adipose tissue) and post-translation level by microRNAs. The activity of LPL is dependent on the nutritional status; in adipose tissue is particularly high in the fed state whereas in heart and skeletal muscles the regulation is tighter.
Lipoprotein lipase plays an important role in the metabolism of TG-rich lipoproteins by hydrolysis of triglycerides, transported by chylomicrons and very low-density lipoproteins (VLDL), to free fatty acids and glycerol. Among several regulators of LPL activity apolipoproteins C-II, C-III and angiopoietin-like proteins 3, 4,8 seem to be the most important. The presence of apolipoprotein C-II on TG-rich and HDL lipoproteins is essential for the activation of lipoprotein lipase (Fig.2) [9].

Under the influence of lipase activity, the VLDL particle loses triglyceride content and shrinks, transforming into LDL. During the transformation of VLDL into LDL, their apolipoprotein content changes. During lipolysis apolipoprotein C-III, which is found mainly on VLDL, is released into the blood stream. Apo-CIII is known as an inhibitor of lipoprotein lipase, however, according to recent data the inhibition of $L P L$ depends on the ratio of apoC-III to apoC-II [10]. Thus apoC-III should be regarded as a factor involved in triglyceride homeostasis. Free 


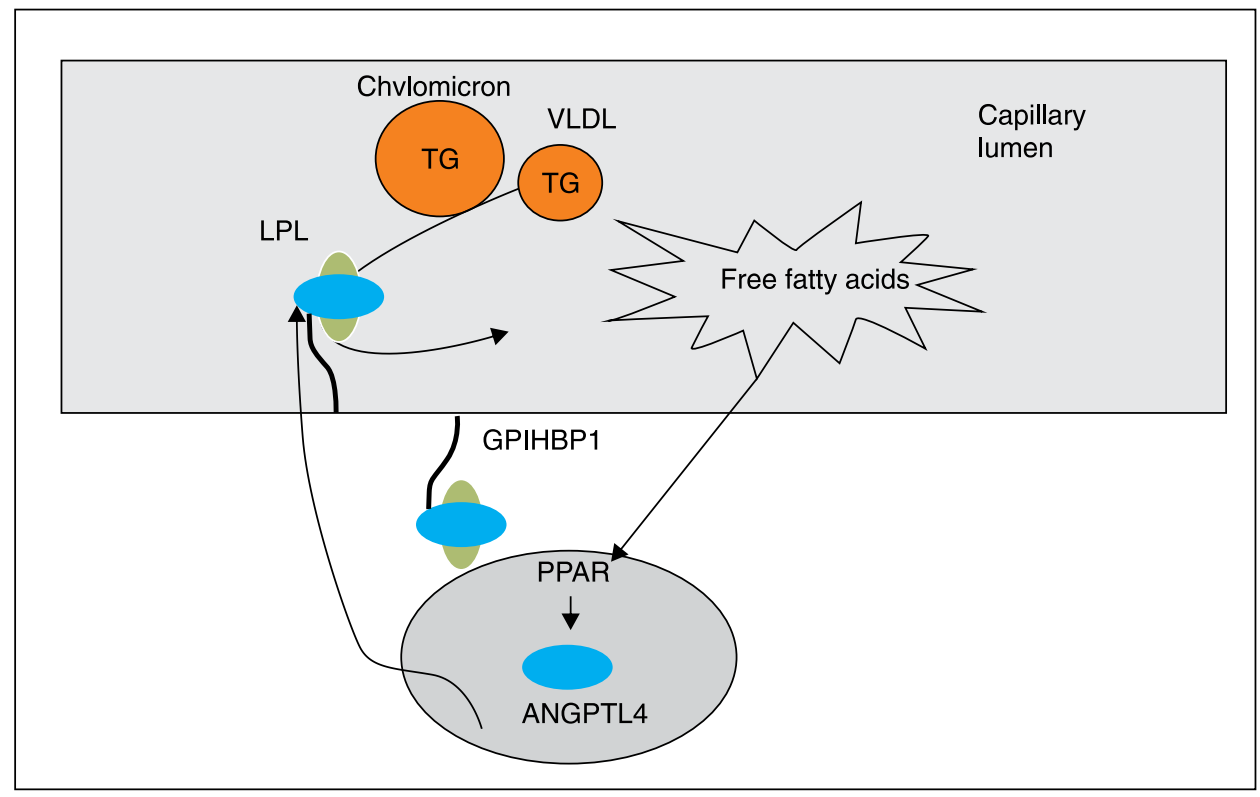

Figure 3. ANGPTL4 as an inhibitor of lipoprotein lipase (LPL) [15], modified by authors

fatty acids formed during lipolysis are further transferred to the adipose tissue or muscles, where they can be used for energy production or stored.

Additionally, LPL is involved in the atherogenesis since it influences the interaction between atherogenic lipids and the surface of endothelial cells of arterial vessel walls [11]. Changes of LPL activity may occur in some pathophysiological processes related to obesity, diabetes, chylomicronemia and atherosclerosis [12].

\section{Angiopoietin-like proteins (ANGPTLs)}

Angiopoietin-like proteins (ANGPTLs) are a group of eight proteins that are structurally similar to the angiopoietin, however, they do not bind to the receptors specific for angiopoietins. Three of these proteins ANGPTL3, ANGPTL4 and ANGPTL8 are related to lipoprotein metabolism as they regulate lipoprotein lipase. ANGPTL3 and ANGPTL4 contain an amino-terminal coiled-coil domain, carboxy-terminal fibrinogen-like domain and a linker. ANGPTL8 is an exception since it does not contain the fibrinogen-like domain. They are released into the circulation from the liver and adipose tissue with exception of ANGPTL3, secreted only from the liver, and named a hepatokine [13]. In the fed state both, ANGPTL3 and ANGPTL8 act together inhibiting lipoprotein lipase. Expression of ANGPTL4 is increased in the fasting state and then ANGPTL4 may inhibit LPL. Although ANGPTLs are structurally similar, they exhibit a slightly different biological activity. ANGTPL3 is regulated by the liver $X$ receptor which acts as a sensor of cholesterol metabolism and lipid biosynthesis, while
ANGPTL4 expression is regulated by the peroxisome proliferator-activated receptors (PPARs) that influence adipocyte differentiation, insulin sensitivity and lipid metabolism [14, 15]. The mechanism of ANGPTL4 activity is based on the inhibition of LPL partly by dissociation of active LPL dimers to an inactive LPL monomer. Transcription of ANGPTL4 is under the control of the peroxisome proliferator-activated receptors (PPARs) and the level of fatty acids (Fig.3).

In tissues such as, for example, a heart, the production of ANGPTL4 is stimulated by fatty acids, which can protect the cells from an excessive fat uptake. LPL, on the surface of endothelial cells, forms a complex with GPIHBP1 which is responsible for the transport and entry of LPL into capillaries in the process of lipolysis. ANGPTL4 is capable of binding and inactivating LPL complexed to GPIHBP1. ANGPTL4 is a strong inhibitor of lipoprotein lipase which hydrolyses triglycerides in chylomicrons and VLDL. By means of this mechanism, the protein inhibits release of free fatty acids and their further uptake by adipose tissue, skeletal muscles and cardiac muscle. It is suggested that all three ANGPTLs have different roles in lipid metabolism. ANGPTL3 seems to be a new treatment target to decrease circulating cholesterol and triglyceride levels in patients with dyslipidemia [16]. Mutations in the gene of ANGPTL3 and ANGPTL8 in humans, leading to inactivation of proteins, were shown to reduce triglyceride and cholesterol levels due to an elevation of LPL activity. Interestingly, similar mutations in ANGPTL4 did not affect significantly lipid levels. Dewey et al. [17] showed in their studies that in 1661 individuals with heterozygous missense mutations of ANGPTL4 protein, the triglycerides level was lower 
by $13 \%$, and the HDL-C level was higher by $7 \%$ than in individuals without this mutation.

ANGPTL3 and ANGPTL4 levels can be determined by commercial enzyme-linked immunosorbent assays [18]. However, due to the fact that ANGPTLs undergo proteolytic cleavage in the circulation, it is important to report which form of these proteins were assayed. Cleavage of ANGPTL3, probably facilitated by ANGPTL8, leads to release of the N-terminal domain from ANGPTL3 and restore LPL activity for TG hydrolysis. ANGPTL4 is also cleaved in the linker region and as ANGPTL3 is present in the circulation in full-length and truncated form [16]. Recently, Morinaga et al reported that circulating full-length form of ANGPTL3 levels were directly and significantly correlated only with C-reactive protein (hsCRP) values and liver enzymes activity when assayed in a population of adult women and men undergoing routine health check-ups [16]. As the cleaved form of ANGPTL3 was found to be the active one, further studies are needed to confirm its association with triglyceride and/or cholesterol reduction. Interestingly, in the same study, a significant positive correlation was found between ANGPTL8 and triglycerides and LDL-C and negative with HDL-C levels, indicating its role in lipid metabolism. What is more, a significant interaction of ANGPTL3 and ANGPTL8 with serum triglyceride levels was shown.

In conclusion, several studies confirm that angiopoietin-like proteins may be potential new biomarkers for the cardiovascular diseases risk assessment $[16,17$, $19,20,21]$. However, in spite of playing an important role in the lipoprotein metabolism, currently, they are not used in the routine diagnostics due to the technical limitations in their measurement.

\section{References}

1. Stanisławska J, Talarska D, Kudlińska A. Porównanie występowania czynników ryzyka choroby niedokrwiennej serca u chorych po przebytym zawale serca do osób bez klinicznych objawów tej choroby Hygeia Public Health. 2014; 41: 127-133.

2. Kappelle PJ, Gansevoort RT, Hillege JL, et al. PREVEND study group. Apolipoprotein B/A-I and total cholesterol/high-density lipoprotein cholesterol ratios both predict cardiovascular events in the general population independently of nonlipid risk factors, albuminuria and C-reactive protein. J Intern Med. 2011; 269(2): 232-242, doi: 10.1111/j.1365-2796.2010.02323.x, indexed in Pubmed: 21129046.

3. Bilen O, Kamal A, Virani SS. Lipoprotein abnormalities in South Asians and its association with cardiovascular disease: Current state and future directions. World J Cardiol. 2016; 8(3): 247-257, doi: 10.4330/wjc v8.i3.247, indexed in Pubmed: 27022456.

4. Pencina MJ, D'Agostino RB, Zdrojewski T, et al. Apolipoprotein B improves risk assessment of future coronary heart disease in the Framin- gham Heart Study beyond LDL-C and non-HDL-C. Eur J Prev Cardiol. 2015; 22(10): 1321-1327, doi: 10.1177/2047487315569411, indexed in Pubmed: 25633587

5. Keller T, Zeller T, Ojeda $F$, et al. Serial changes in highly sensitive troponin I assay and early diagnosis of myocardial infarction. JAMA. 2011; 306(24): 2684-2693, doi: 10.1001/jama.2011.1896, indexed in Pubmed: 22203537

6. Walldius G, Jungner I, Holme I, et al. High apolipoprotein B, low apolipoprotein A-I, and improvement in the prediction of fatal myocardial infarction (AMORIS study): a prospective study. The Lancet. 2001; 358(9298): 2026-2033, doi: 10.1016/s0140-6736(01)07098-2.

7. Vakkilainen J, Mäkimattila S, Seppälä-Lindroos A, et al. Endothelial dysfunction in men with small LDL particles. Circulation. 2000; 102(7): 716-721, indexed in Pubmed: 10942737.

8. Muraba Y, Koga T, Shimomura Y, et al. The role of plasma lipoprotein lipase, hepatic lipase and GPIHBP1 in the metabolism of remnant lipoproteins and small dense LDL in patients with coronary artery disease. Clin Chim Acta. 2018; 476: 146-153, doi: 10.1016/j.cca.2017.11.021, indexed in Pubmed: 29174344

9. Wong $\mathrm{H}$, Davis RC, Thuren T, et al. Lipoprotein lipase domain function. J Biol Chem. 1994; 269(14): 10319-10323, indexed in Pubmed: 8144612

10. Dallinga-Thie GM, Kroon J, Borén J, et al. Triglyceride-Rich Lipoproteins and Remnants: Targets for Therapy? Curr Cardiol Rep. 2016; 18(7): 67, doi: 10.1007/s11886-016-0745-6, indexed in Pubmed: 27216847.

11. Kolovou GD, Kolovou V, Panagiotakos DB, et al. Study of common variants of the apolipoprotein $\mathrm{E}$ and lipoprotein lipase genes in patients with coronary heart disease and variable body mass index. Hormones (Athens). 2015; 14(3): 376-382, doi: 10.14310/horm.2002.1572, indexed in Pubmed: 26188224.

12. Xie Li, Li YM. Lipoprotein Lipase (LPL) Polymorphism and the Risk of Coronary Artery Disease: A Meta-Analysis. Int J Environ Res Public Health. 2017; 14(1), doi: 10.3390/ijerph14010084, indexed in Pubmed: 28275220

13. Santulli G. Angiopoietin-like proteins: a comprehensive look. Front Endocrinol (Lausanne). 2014; 5: 4, doi: 10.3389/fendo.2014.00004, indexed in Pubmed: 24478758

14. Cinkajzlová A, Mráz M, Lacinová Z, et al. Angiopoietin-like protein 3 and 4 in obesity, type 2 diabetes mellitus, and malnutrition: the effect of weight reduction and realimentation. Nutr Diabetes. 2018; 8(1): 21, doi: 10.1038/s41387-018-0032-2, indexed in Pubmed: 29695708.

15. Tikka A, Jauhiainen M. The role of ANGPTL3 in controlling lipoprotein metabolism. Endocrine. 2016; 52(2): 187-193, doi: 10.1007/s12020015-0838-9, indexed in Pubmed: 26754661.

16. Morinaga J, Zhao J, Endo M, et al. Association of circulating ANGPTL 3,4 , and 8 levels with medical status in a population undergoing routine medical checkups: A cross-sectional study. PLoS One. 2018; 13(3): e0193731, doi: 10.1371/journal.pone.0193731, indexed in Pubmed: 29538435

17. Dewey FE, Gusarova V, O'Dushlaine C, et al. Inactivating Variants in ANGPTL4 and Risk of Coronary Artery Disease. N Engl J Med. 2016; 374(12): 1123-1133, doi: 10.1056/NEJMoa1510926, indexed in Pubmed: 26933753

18. Dijk W, Beigneux AP, Larsson M, et al. Angiopoietin-like 4 promotes intracellular degradation of lipoprotein lipase in adipocytes. J Lipid Res. 2016; 57(9): 1670-1683, doi: 10.1194/Jr.M067363, indexed in Pubmed: 27034464

19. Abid K, Trimeche T, Mili D, et al. ANGPTL4 variants E40K and T266M are associated with lower fasting triglyceride levels and predicts cardiovascular disease risk in Type 2 diabetic Tunisian population. Lipids Health Dis. 2016; 15: 63, doi: 10.1186/s12944-016-0231-6, indexed in Pubmed: 27004807

20. Coding Variation in ANGPTL4, LPL, and SVEP1 and the Risk of Coronary Disease. New England Journal of Medicine. 2016; 374(19): 1898-1898, doi: 10.1056/nejmx160012.

21. Drenos F Davey Smith G, Ala-Korpela M et al Metabolic Characterization of a Rare Genetic Variation Within APOC3 and Its Lipoprotein Lipase-Independent Effects. Circ Cardiovasc Genet. 2016; 9(3): 231-239, doi: 10.1161/CIRCGENETICS.115.001302, indexed in Pubmed: 27114411 